\title{
Atomistic understanding of structural evolution in alnico alloys using advanced AC-STEM
}

\author{
Lin Zhou $^{1}$, Wei Tang ${ }^{1}$, Ping Lu ${ }^{2}$, I. E. Anderson ${ }^{1}$, M. J. Kramer ${ }^{1}$
}

${ }^{1}$ Ames Lab, Ames, IA 50011

${ }^{2}$ Sandia National Laboratories, Albuquerque, NM 87185

Understanding architecture in materials down to atomic level is a key for design and fabrication of advanced materials as devices become smaller and interfacial effects dominate performance. Aberration-corrected STEM (AC-STEM) combined with energy-loss and energy-dispersive xray spectroscopic techniques (EELS and EDS) provide the necessary quantitative elemental information with sub-nanometer spatial resolution. Utilizing advanced TEM holders, which can provide materials with external effects during imaging process, including thermal, stress/strain, electric field and magnetic field et. al., in addition, enables characterizing materials with both spatially and temporally resolved perspective. This paper describes an overview of our recent progress in a characterizing a magnetic alloy, alnico, using state-of the-art electron beam characterization tools located at the Sensitive Instrument Facility (SIF) in Ames Laboratory.

Alnico alloys (containing $\mathrm{Al}, \mathrm{Ni}, \mathrm{Co}, \mathrm{Ti}, \mathrm{Fe}$, and $\mathrm{Cu}$ ) show great potential for replacing the best commercial Nd-based rare-earth alloys for applications above $200^{\circ} \mathrm{C}$. The coercivity of alnico depends on its nanostructure, in particular, the composition and morphology of the Al-Ni-rich, $\mathrm{Fe}-\mathrm{Co}$-rich and $\mathrm{Cu}$-enriched phases that developed during spinodal decomposition. The spinodal decomposed structures are developed after a lengthy heat-treatment process, including high temperature solutionization $\left(\sim 1250^{\circ} \mathrm{C}\right)$, magnetic-field annealing $\left(\sim 840^{\circ} \mathrm{C}\right)$ to induce anisotropic growth of the SD phases, and drawing $\left(\sim 600-700^{\circ} \mathrm{C}\right)$ to optimize the magnetic properties. Both ex situ and in situ TEM are performed to better elucidate the relationship between processing conditions, microstructure and property. Figure 1 shows results on commercial alnico 9 alloy. The $\mathrm{Cu}$-enriched phase was discovered to have a defective structure (Figs. 1a) with a gradual increase of $\mathrm{Cu}$-concentration into the center of the precipitate. Geometric phase analysis (GPA) from Fig.1a indicates the Al-Ni-rich phase is under tensile strain (Fig. 1b). Moreover, chemical composition in this alloy at individual lattice sites was determined by TEM. In the B2 Fe-Co-rich phase the sites exhibit $\sim 76$ at.\% Fe and $\sim 40 \%$ Fe ordering in the two sites (Fig. 1c), and, in the L2 1 -ordered Al-Ni-rich phase, the A-sites, BI-sites and BII-sites have compositions of 48 at. $\%$ $\mathrm{Ni}$ and $\mathrm{Co}, \mathrm{Al}$, and $\sim 80$ at. $\% \mathrm{Ti}$ and $\mathrm{Fe}$, respectively $[1,2]$. A Ni-enriched/Ti-deficient region at the $\mathrm{FeCo} / \mathrm{AlNi}$-rich interface was also detected.

Figure 2 (a) and (b) show high-resolution STEM image and corresponding EDS elemental mapping of $\mathrm{Cu}$ in an alnico alloy after solutionization. The $\mathrm{Cu}$-enriched phase has segregated out and formed a coherent lattice structure $(b c c)$ with the $\mathrm{L} 2{ }_{1}$ matrix. Analysis on a sample with further magnetic field annealing $\left(840^{\circ} \mathrm{C}\right)$ and drawing $\left(650^{\circ} \mathrm{C}\right)$ showed that the $\mathrm{Cu}$-enriched phase is coarsened, as shown in Fig. 2 (c, d). The $\mathrm{Cu} / \mathrm{AlNi}$ interface is semicoherent. Shear along the [110] direction was observed in the $\mathrm{Cu}$-enriched phase, which indicating deviation of their lattice from $b c c$ crystal structure. This change in microstructure is accompanied by substantial increase of coercivity of the alloy from 35Oe to 1707 Oe between solutionized and full heat treated samples. 
Research was supported by U.S. DOE, Office of Basic Energy Sciences, Materials Science and Engineering and Office of Energy Efficiency and Renewable Energy (EERE), under its Vehicle Technologies Program, through the Ames Laboratory, Iowa State University under contract DEAC02-07CH11358. Sandia National Laboratories is a multi-program laboratory managed and operated by Sandia Corporation, a wholly owned subsidiary of Lockheed Martin Corporation, for the US Department of Energy's National Nuclear Security Administration under contract DEAC04-94AL85000.

[1] Lin Zhou, M. K. Miller, Ping Lu, Liqin Ke, R. Skomski, M. McCartney, D. Smith, H. Dillon, Q. Xing, A. Palasyuk, S. Constantinides, R.W. McCallum, I. E. Anderson, V. Antropov, and M. J. Krame, Acta Materilia, 74, (2014), 224.

[2] P. Lu, L. Zhou L, M. Kramer, D. J. Smith, Scientific Reports 4 (2014) 3945.
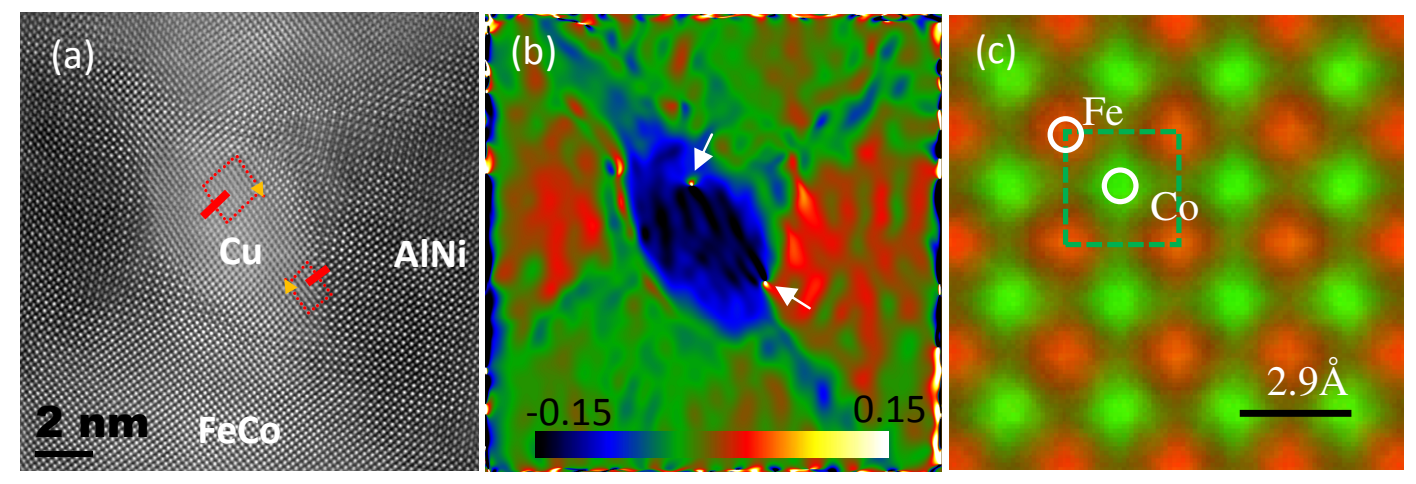

Fig. 1 - (a) High-resolution HAADF-STEM image of alnico taken along [001] around a $\mathrm{Cu}$-enriched precipitate. Alternating contrast of (100) planes in the AlNi-rich phase confirmed chemical ordering of this intermetallic. Two dislocations are clearly observed, as indicated by red line with corresponding burgers loop; (b) GPA strain (Exx) map of image (a) showing the AlNi-rich phase is under tensile strain. High compressive strain is observed in the $\mathrm{Cu}$-enriched phase. The position of misfit dislocations is indicated by white arrows. (c) Composite color map of $\mathrm{Fe}-\mathrm{K} \alpha$ (red) and $\mathrm{Co}-\mathrm{K} \alpha$ (green) showing ordering in FeCo-rich bcc phase. [2]

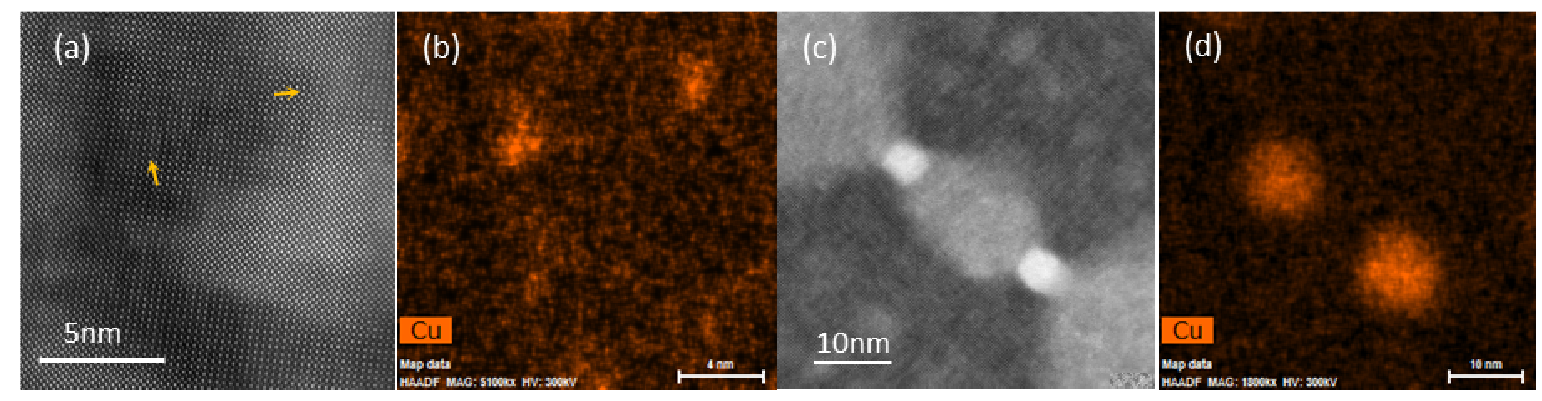

Fig. 2 - High-resolution STEM image and corresponding EDS Cu elemental mapping of an alnico alloy after solutionization at $1250^{\circ} \mathrm{C}(\mathrm{a}, \mathrm{b})$ and further magnetic field annealing $\left(840^{\circ} \mathrm{C}\right)$ and $\operatorname{draw}\left(650^{\circ} \mathrm{C}\right)(\mathrm{c}, \mathrm{d})$. 